American Journal of Applied Sciences 6 (1): 24-29, 2009

ISSN 1546-9239

(C) 2009 Science Publications

\title{
Pitch and Timbre Determination of the Angklung
}

\author{
Mohd Ridzuwary Mohd Zainal, Salina Abdul Samad, \\ Aini Hussain and Che Husna Azhari \\ Faculty of Engineering, \\ University Kebangsaan Malaysia (UKM), 43600 Bangi, Selangor, Malaysia
}

\begin{abstract}
This research describes the pitch and timbre determination of the angklung, a musical instrument made entirely out of bamboo. An angklung has two main parts: the frame and the rattle tubes. The pitch of the rattle tubes can be determined using a formula that takes into consideration the length and diameter of the air resonator. This is compared with the results obtained using sound analysis with the fast Fourier transform as well as with measured results. The coupling effects of having two rattles on the pitch and timbre are investigated. It is found that the pitch of the angklung is closely related to the fundamental frequency of air resonance in the bamboo tubes of the angklung rattles. Therefore, the pitch of an angklung can be estimated by calculating that fundamental frequency using information from the length and diameter of the closed cylinder air column of each rattle. The timbre of the angklung is also determined to be a mix of the sound output from each of its individual rattles. The timbre has an identifying characteristic of having two prominent peaks with each one corresponding to the pitch of each rattle.
\end{abstract}

Key words: Digital signal processing, music synthesis

\section{INTRODUCTION}

An angklung is a rattle like musical instrument that is made entirely from bamboo. The angklung sound is produced from an impact mechanism within its body structure without the use of any tensed strings or stretched membranes. Therefore, the angklung is classified as a percussion musical instrument of the group idiophone along with the xylophone and the gong. Figure 1 shows the front view of the angklung.

The angklung is generally supposed to originate from West Java. According to folklore, angklung was a musical instrument of agricultural festivals and was also used during the festivities to arouse the fighting spirits of soldiers. It was also associated in Java with hobby-horse dancing ${ }^{[1,2]}$. In the $1920 \mathrm{~s}$, it was used as children's toy and then in the 1930s, it was used by beggars to attract passers by. Daeng Sutigna of Bandung, a musician, then started to resurrect and popularise the angklung. He introduced tunes similar to Western music, composed modern arrangements and recruited more angklung enthusiasts. Angklungs normally found nowadays are tuned to the Western diatonic scale which differs from the traditional pentatonic scale ${ }^{[3]}$.

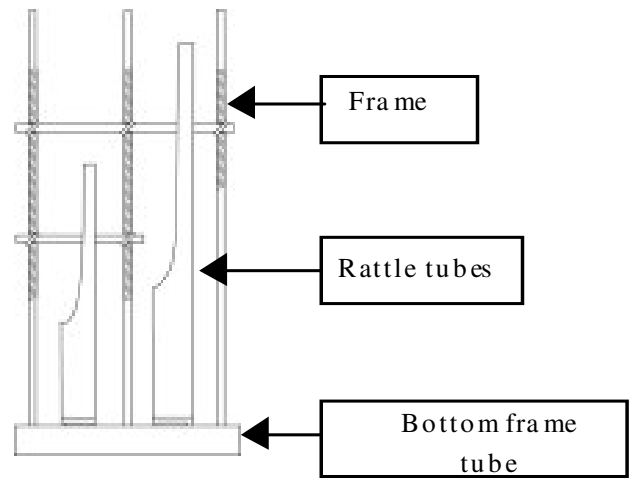

Fig. 1: Front view of an angklung

Three species of bamboo have been reported to be used in angklung production. The first is the bambu tutul or Bambusa vulgaris Schrad. ex J.C. Wendl. var. maculata Widjaja. However, recently this type of bamboo is rarely used for the angklung. The second species is the bambu hitam or Gigantochloa aff. atter (Hassk.) Kurz ex Munro, which has a distinct leaf anatomy from the true G. atter or bambu temen. This second species is the most used for Sundanese bamboo musical instruments including the angklung. The third species is the bambu

Corresponding Author: Mohd Ridzuwary Mohd Zainal, Department of Electrical, Electronic and Systems Engineering, Faculty of Engineering, Universiti Kebangsaan Malaysia (UKM), 43600 Bangi, Selangor, Malaysia Tel: +603-89216317 Fax: +603-89216146 
apus or Gigantochloa apus B1. ex Schultes f., which is less favorable because its tubes are not straight and the nodes has little swellings that cause some disturbance in the sound it produces ${ }^{[3]}$.

The angklung's physical parameters and sound is analyzed in this research. Analyzing the angklung is important to recognize the main characteristics that make up the unique sound of the angklung. This will help to make the instrument more accessible and easily utilized in the modern digital music scene. This research will describe how the pitch of an angklung can be determined using physical measurements of the angklung. The length and diameter of the angklung rattle air column are used to calculate the angklung's pitch. This research will also examine the timbre of an angklung and determine the main characteristics that distinguish sound of the angklung from other instruments.

\section{MATERIALS AND METHODS}

Every component of an angklung may have its traditional name, but in this research, these components will be given a descriptive name. An angklung has two main parts, the frame and the rattle tubes as shown in Fig. 1. The frame's functions are to hold the rattle tubes and as a place for an angklung player to hold the angklung.

The rattle tubes are the main sound generators for an angklung. The tubes are made from a segment of a bamboo with one of its ends still closed by its node. Part of the segment near the open end of the tube is removed forming the tongue of the rattle tube. A pair of small protuberances is left at the closed end of the tube which we will call tines. These rattle tubes are suspended vertically in the angklung frame. The tubes are suspended in such a way that the tines can slide easily and loosely inside slits made in the bottom frame tube. The bottom frame tube is also made from a bamboo segment but both its ends are open. Figure 2 shows the rattle tube of an angklung ${ }^{[4]}$.

The angklung is played by holding the frame with one hand and shaking the bottom frame tube sideways with the other hand. This sideways motion will cause the rattle tubes to swing and the tines will strike the end of their respective slits. The angklung can also be played with the frame tilted sideways to shake it just once. Note that each angklung is made to produce just one musical note. Therefore, a whole ensemble of angklung players is needed to play any particular melody. Nevertheless, it is possible to play a melody with just a single player by using a device that holds multiple angklung and allows the player to play all of them by himself.
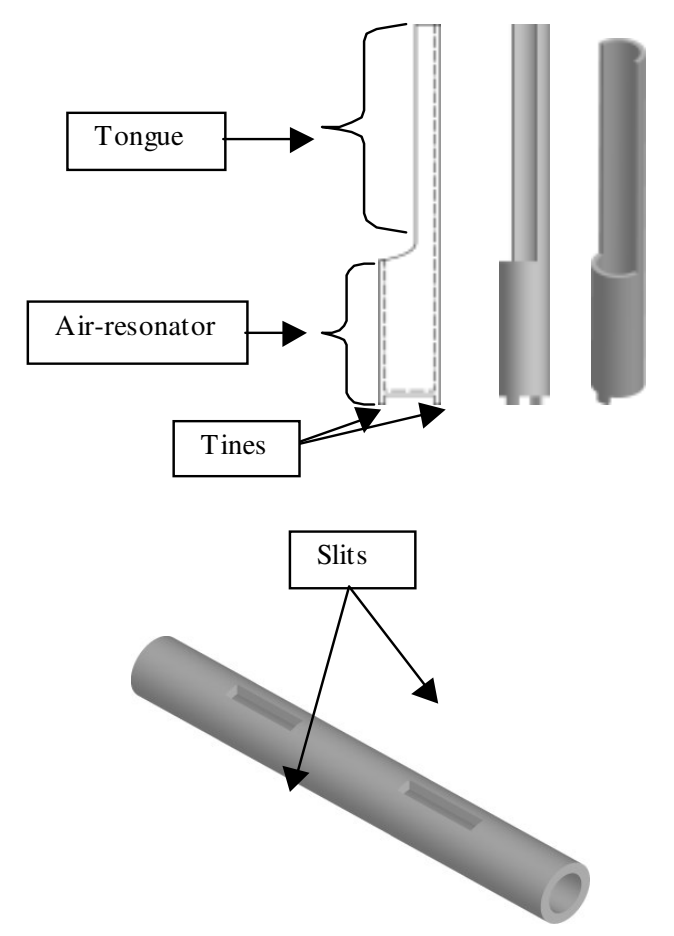

Fig. 2: Rattle tube of an angklung

Tuning of an angklung mainly depends on two measurements, the length of the air resonator and the length of the tongue of the rattle tubes. The air resonator acts like an amplifier in that it amplifies the frequency of sound that matches the natural frequency of the air vibrating inside the resonator. The length of the tongue determines the natural frequency of the whole rattle tube vibration. Generally, the longer the whole rattle tube, the lower the pitch of the generated sound. The rattle tube can be fine tuned by carving parts of the tongue. Sharpening or raising the pitch can be achieved by shortening the tongue at its end. Flattening or lowering the pitch can be done by carving away the part where the tongue and the air resonator meet, thus making the effective tongue length slightly longer.

To determine the reference frequency values corresponding to an angklung pitch, a set is used consisting of eight angklungs with eight different pitches that make up a full octave without accident notes ranging from $\mathrm{C} 5$ to $\mathrm{C} 6$. This reseach uses the tempered scale for comparison purposes, with the A above the middle $\mathrm{C}$ being equal to $440.00 \mathrm{~Hz}$ and with $\mathrm{C} 4$ being the middle $\mathrm{C}$. Table 1 gives the frequency for each corresponding angklung pitch in the set.

This research uses the cents notation for subdividing the basic interval of the tempered scale. Cents is calculated using the relationship: 
Am. J. Applied Sci., 6 (1): 24-29, 2009

Table 1: Corresponding frequency values for C5-C6 using tempered scale

\begin{tabular}{lc}
\hline Pitch & Standard frequency (Hertz) \\
\hline C5 & 523.25 \\
D5 & 587.33 \\
E5 & 659.26 \\
F5 & 698.46 \\
G5 & 783.99 \\
A5 & 880.00 \\
B5 & 987.77 \\
C6 & 1046.50 \\
\hline
\end{tabular}

$$
\frac{\mathrm{f}_{2}}{\mathrm{f}_{1}}=2 \frac{\phi}{1200}
$$

with $\phi$ is cents, $f_{1}$ is the reference frequency and $f_{2}$ is the interested frequency value ${ }^{[5-7]}$.

Rattle modeling: The air resonator directly affects the sound of an angklung. When the tine of an angklung rattle hits the bottom frame tube, sound is introduced at the bottom of the air resonator. The sound wave will travel back and forth between the mouth and the bottom of the air resonator resonating at the air resonator fundamental frequency and odd harmonics.

A closed cylindrical air resonator will produce resonant standing waves at the fundamental frequency and at odd harmonics. In the case of an angklung, the fundamental frequency is the pitch the angklung is tuned to. The fundamental frequency can be calculated as follows:

$$
\mathrm{f}=\frac{\mathrm{nv}}{4(\mathrm{~L}+0.305 \mathrm{~d})}, \mathrm{n}=1,3,5, \ldots
$$

where, $\mathrm{f}$ is the frequency in Hertz, $\mathrm{n}$ is the harmonic number, $v$ is the speed of sound in air, $L$ is the length of the air resonator and $d$ is the diameter of the air resonator. Figure 3 shows the parameters associated with air resonance in a closed cylinder ${ }^{[7,8]}$.

An important method of processing and analyzing a sound signal is to look at the signal's frequency content. The Fast Fourier Transform (FFT) method can be used for this purpose. FFT is based on the complex Discrete Fourier Transform (DFT) equation

$$
\begin{aligned}
& \operatorname{Re} X[k]=\sum_{i=0}^{N-1} x[i] \cos (2 \pi k i / N) \\
& \operatorname{Im} X[k]=\sum_{i=0}^{N-1} x[i] \sin (2 \pi k i / N)
\end{aligned}
$$

with index $\mathrm{k}$ running from $0-\mathrm{N} / 2$ where $\mathrm{N}$ is the number of sample ${ }^{[9-12]}$.

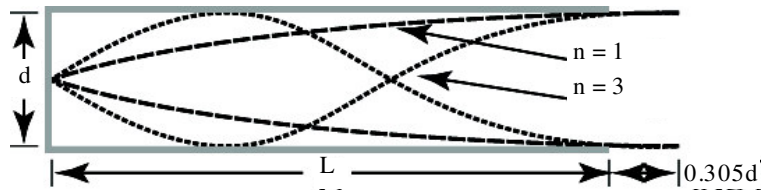

Fig. 3: Air resonance in a closed cylinder

Another way of examining the frequency content in a signal is to see how the frequency changes over time. The the short-time Fourier transform (STFT) can be used for this purpose. This method breaks the input signal into a sequence of brief segments with each segment multiplied by a windowing function. Smooth bell-shaped windowing functions are usually used to reduce distortion that occurs during windowing. FFT is then applied to each segment resulting in a series of frequency spectrum for every short time window of the input signal, hence the name short-time Fourier transform. The resulting transform is represented as a frequency over time figure called a spectrogram with colour intensity representing frequency magnitude. During the segmentation, the windows are chosen to overlap one another to capture the signals without gaps caused by the bell-shaped windows ${ }^{[9,12]}$. All the angklung sound for analysis is sampled at a sampling frequency of $44100 \mathrm{~Hz}$ with 16 bit resolution.

\section{RESULTS AND DISCUSSION}

The fundamental frequency for the primary rattles of each angklung is calculated based on the calculation of air resonance in a closed cylinder. The results are given in the Table 2 with $\mathrm{v}=340.29 \mathrm{~m} \mathrm{sec}^{-1}$.

Sound from the primary rattles of the angklungs are sampled and collected. The rattle is only allowed to strike once to capture the full length of the rattle sound. A rattle sound played this way would have a length of between $80 \mathrm{~ms}$ to $140 \mathrm{~ms}$. The rattle sound cannot reach its full length in a real angklung performance since the speed that the angklung is shaken will cause the rattle to strike again before its previous sound completely dies off. The samples are analyzed using FFT to determine the prominent frequency that can be chosen as the rattles' pitch. FFT is computed with a resolution of 65536 points using zero padding. The high resolution is possible because the samples are very short and data handling is manageable.

Figure 4 shows the waveform of an gklung C5 primary rattle sample, to illustrate a typical result. The frequency spectrum shows that each primary rattle sample has a single prominent frequency, which we name $f_{\text {primary. }}$ Harmonics of that frequency are either very weak or non existent. Some inharmonic peaks are observed to be present in the spectrum. The most 
Am. J. Applied Sci., 6 (1): 24-29, 2009

Table 2: Calculated fundamental frequency for the primary rattles

\begin{tabular}{lclc}
\hline & Primary rattle & \\
Angklung & - & & \\
pitch & $\mathrm{L}(\mathrm{mm})$ & $\mathrm{d}(\mathrm{mm})$ & $\mathrm{f}_{1}(\mathrm{Hertz})$ \\
\hline C5 & 158 & 31 & 508.03 \\
D5 & 136 & 32 & 583.65 \\
E5 & 120 & 26 & 664.99 \\
F5 & 112 & 25 & 711.16 \\
G5 & 95 & 25 & 828.96 \\
A5 & 86 & 24 & 911.62 \\
B5 & 80 & 23 & 977.68 \\
C6 & 72 & 23 & 1076.66 \\
\hline
\end{tabular}

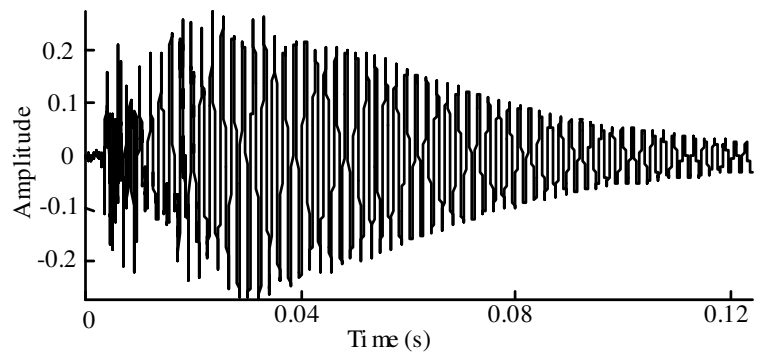

Fig. 4: Waveform of angklung C5 primary rattle sample

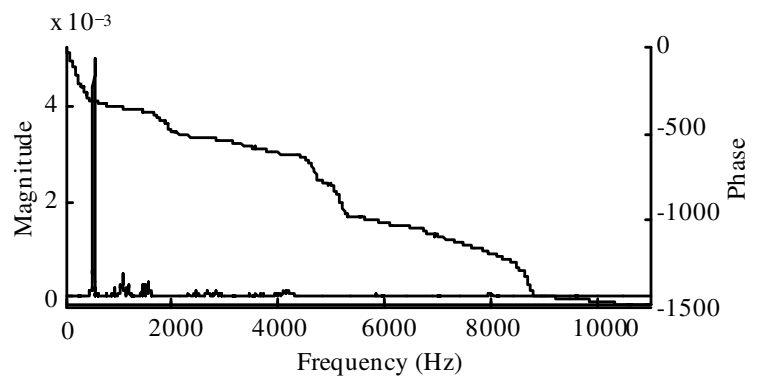

Fig. 5: FFT result of angklung C5 primary rattle sample

significant inharmonic partial is at $2.45 \mathrm{f}_{\text {primary }}$, which can sometimes have a higher magnitude than the $\mathrm{f}_{\text {primary }}$. Nevertheless, that phenomenon is not common and the strength of the partials is usually like the one shown in Fig. 5. By plotting the spectrogram of the sound using STFT, we can see that $f_{\text {primary }}$ is persistent along the sample length as shown in Fig. 6. Therefore, we can take $f_{\text {primary }}$ as the rattle's pitch.

Table 3 shows a comparison of $f_{\text {primary }}$ with the calculated fundamental resonance of each rattle of Table 2. The $\mathrm{f}_{\text {primary }}$ is shown as a range of maximum and minimum of the collected samples. The variation is caused by the lack of a steady-state or a sustain period in the waveform, which can be seen in Fig. 4. Thus, the sound vibration cannot settle to a stable frequency before losing all of its energy. On average, the maximum difference between the calculated
Table 3: Comparison of $\mathrm{f}_{\text {primary }}$ with fundamental air resonance for each primary rattle

\begin{tabular}{lcc}
\hline $\begin{array}{l}\text { Angklung } \\
\text { pitch }\end{array}$ & $\mathrm{f}_{\text {primary (range) }}$ & $\begin{array}{l}\text { Calculated fundamental } \\
\text { resonance }\end{array}$ \\
\hline C5 & $521.51-524.20$ & 508.03 \\
D5 & $583.42-595.53$ & 583.65 \\
E5 & $659.45-666.18$ & 664.99 \\
F5 & $699.83-707.90$ & 711.16 \\
G5 & $787.98-797.40$ & 828.96 \\
A5 & $894.30-904.39$ & 911.62 \\
B5 & $983.13-1000.20$ & 977.68 \\
C6 & $1061.18-1081.37$ & 1076.66 \\
\hline
\end{tabular}

Table 4: Calculated fundamental frequencies for secondary rattles

\begin{tabular}{llll}
\hline & \multicolumn{2}{l}{ Secondary rattle } & \\
\cline { 2 - 3 } Angklung pitch & $\mathrm{L}(\mathrm{mm})$ & $\mathrm{d}(\mathrm{mm})$ & $\mathrm{f}_{1}(\mathrm{-}$ Hertz) \\
\hline C5 & 74 & 18 & 1070.23 \\
D5 & 64 & 20 & 1213.59 \\
E5 & 58 & 18 & 1339.94 \\
F5 & 53 & 19 & 1446.93 \\
G5 & 47 & 16 & 1639.79 \\
A5 & 42 & 16 & 1814.69 \\
B5 & 36 & 15 & 2096.67 \\
C6 & 34 & 14 & 2222.96 \\
\hline
\end{tabular}

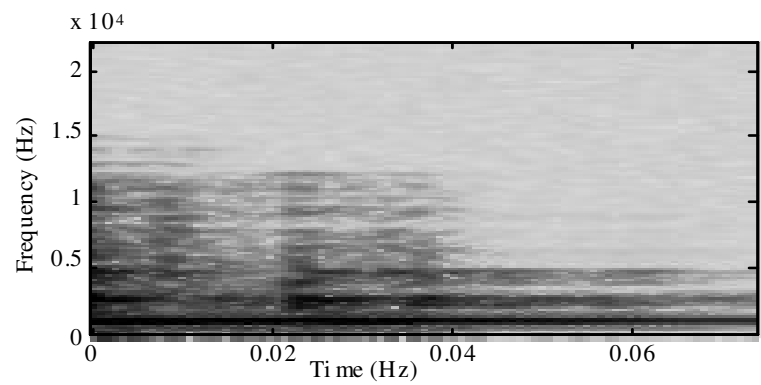

Fig. 6: Spectrogram of angklung C5 primary rattle sample

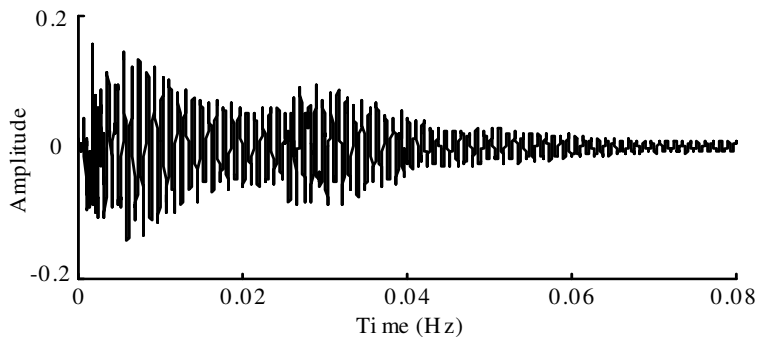

Fig. 7: Waveform of angklung C5 combined secondary rattle sample

fundamental frequencies of air resonance with $\mathrm{f}_{\text {primary }}$ is 46.75 cents.

Similar analysis is also conducted on the secondary rattle of each angklung. Table 4 and Fig. 7-9 are the results of the analysis. $\mathrm{f}_{\text {secondary }}$ is the prominent 


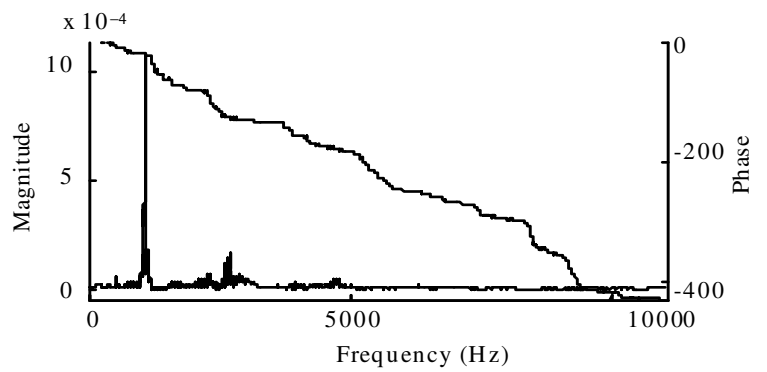

Fig. 8: FFT result of angklung C5 combined secondary rattle sample

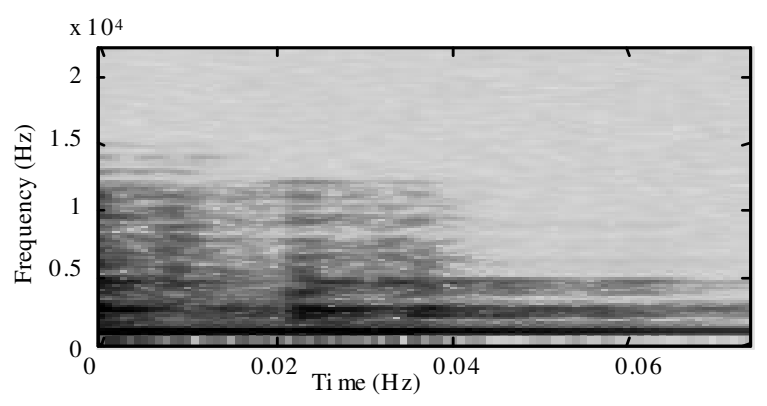

Fig. 9: Spectrogram of angklung C5 combined secondary rattle sample

Table 5: Comparison of $\mathrm{f}_{\text {secondary }}$ with fundamental air resonance for each secondary rattle

\begin{tabular}{lll}
\hline $\begin{array}{l}\text { Angklung } \\
\text { pitch }\end{array}$ & $\mathrm{f}_{\text {secondary }}$ & $\begin{array}{l}\text { Calculated fundamental } \\
\text { resonance }\end{array}$ \\
\hline C5 & $1068.59-1079.35$ & 1070.23 \\
D5 & $1175.58-1193.07$ & 1213.59 \\
E5 & $1337.75-1344.48$ & 1339.94 \\
F5 & $1396.29-1413.12$ & 1446.93 \\
G5 & $1587.40-1597.49$ & 1639.79 \\
A5 & $1779.85-1781.20$ & 1814.69 \\
B5 & $2011.34-2023.45$ & 2096.67 \\
C6 & $2102.18-2116.98$ & 2222.96 \\
\hline
\end{tabular}

frequency of the secondary rattles and is also classified as the pitch for each rattle.

The results for the secondary rattle analysis are also similar with the results for the primary rattle. The main difference is that for every angklung, $\mathrm{f}_{\text {secondary }}$ is

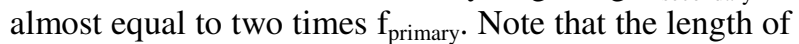
the secondary rattle samples is also shorter than the primary.

Table 5 shows a comparison of $f_{\text {secondary }}$ with the calculated fundamental resonance of Table 4. The average maximum difference between the calculated fundamental resonance and $\mathrm{f}_{\text {secondary }}$ is 26.75 cents.

Each angklung is sampled again but this time with both rattles playing. The coupling effects of the rattles gives a higher total amplitude on the sound output

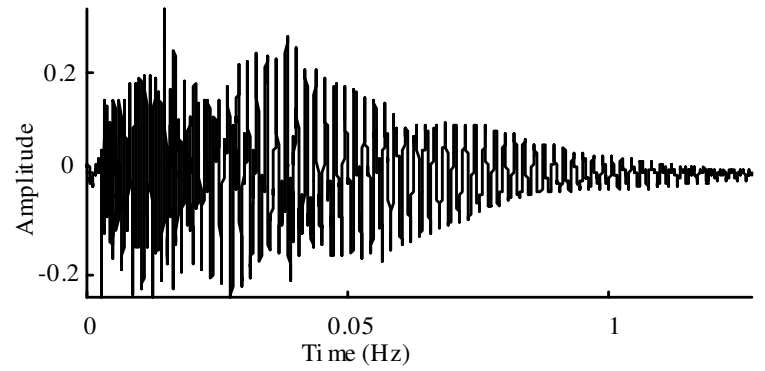

Fig. 10: Waveform of angklung C5 combined primary and secondary rattles sample

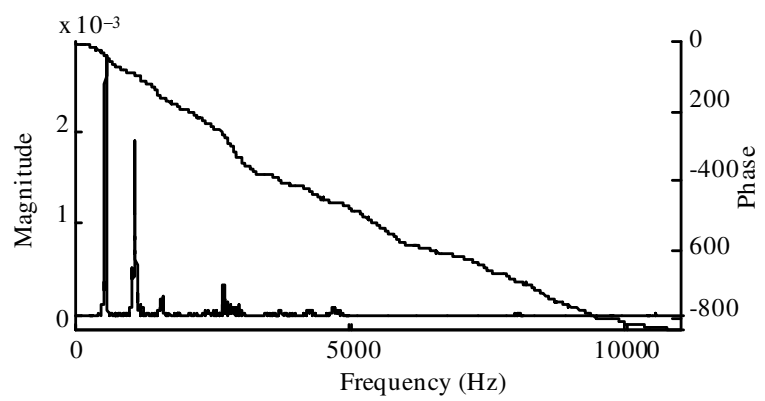

Fig. 11: FFT result of angklung C5 combined primary and secondary rattles sample

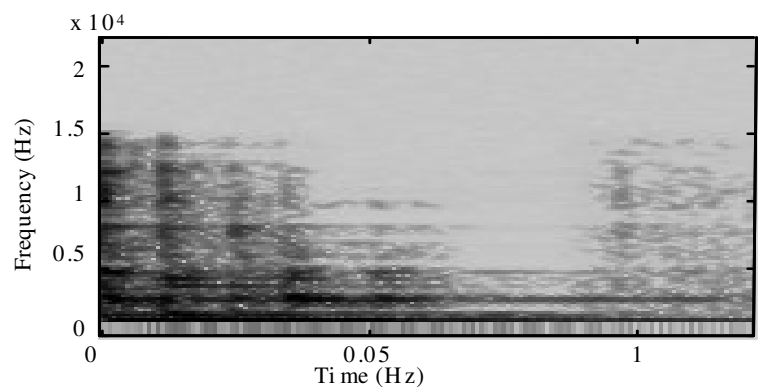

Fig. 12: Spectrogram of angklung C5 combined primary and secondary rattles sample

compared to playing the angklung with a single rattle. The coupling of the rattles also creates a sound output with a more irregular amplitude envelope such as shown in Fig. 10. This can be compared with Fig. 4 and 7.

Figure 11 and 12 show the FFT and spectrogram results for an angklung C5 played with combined rattles. Two main peaks are clearly seen with each corresponding to $\mathrm{f}_{\text {primary }}$ and $\mathrm{f}_{\text {secondary }}$ for the particular angklung. The $2.45 \mathrm{f}$ partial mentioned earlier are also present in the spectrum but the partial for the primary rattle cannot be seen clearly because of its close proximity with $\mathrm{f}_{\text {secondary }}$. 
Am. J. Applied Sci., 6 (1): 24-29, 2009

Table 6: Pitch of the angklung played with both rattles

\begin{tabular}{llc}
\hline Intended pitch & Pitch of samples & $\begin{array}{c}\text { Equivalent frequency } \\
\text { (cents notation) }\end{array}$ \\
\hline C5 & C5-6-C5+10 & $521.44-526.28$ \\
D5 & D5-6-D5+11 & $585.30-591.07$ \\
E5 & E5+4-E5+36 & $660.78-673.11$ \\
F5 & F5+4-F5+20 & $700.08-706.58$ \\
G5 & G5+11-G5+41 & $788.99-802.78$ \\
A5 & A5-9-A5+3 & $875.44-881.53$ \\
B5 & B5+28-B5+41 & $1003.88-1011.44$ \\
C6 & C6+0-C6+22 & $1046.50-1059.88$ \\
\hline
\end{tabular}

Table 6 shows the pitch of the angklung played with both rattles which is the normal playing mode. The pitch of the angklung played with combined rattles is equal to $f_{\text {primary }}$. Since $f_{\text {secondary }}$ is tuned to be twice $f_{\text {primary }}, f_{\text {secondary }}$ has taken the role of becoming the second harmonic of $f_{\text {primarry }}$ in the combined rattle output sound. This has the effect of emphasizing $f_{\text {primary }}$ as the pitch of the angklung. The timbre for an angklung is identified to have two frequency peaks, one being the pitch and the second is about the second harmonic of the first. This shows that the timbre of the angklung is a mix of its individual rattles. Thus, the partials of the respective rattle are also present in the angklung sound. There are also differences between playing the angklung with only one of its rattles than with playing the angklung with both rattles. The angklung sounds fuller and individual attacks during impact of the rattles are less noticeable when playing with both rattles.

\section{CONCLUSION}

The pitch and timbre of an angklung set have been determined in this research. The fundamental frequency of air resonance in each angklung rattle was calculated using the length and the diameter of the air column of the rattles. The calculated fundamental frequency of each angklung rattle was then compared with the pitch of the sound samples collected from the respective rattle. The comparison shows that the fundamental frequency of air resonance in the rattle can be used to estimate the pitch of an angklung with a tolerance of less then 60 cents with a few exceptions. The exceptions are caused by the natural shape of bamboo that differs from the effective length and diameter of the air column to that of an ideal open cylinder. The timbre of the angklung was also analysed and two main features can be observed. The first feature is that for every angklung with a rattle pair, the sound output will have two main peaks in the frequency spectrum with each peak corresponding to the pitch of each rattle. The second feature is that there are inharmonic partials for each of the peak mentioned, with the most obvious being 2.45 times respective of the peak frequency.

\section{REFERENCES}

1. Taylor, E., 1990. Musical instruments of SouthEast Asia. Oxford University Press, Singapura.

2. Mohd, Ghouse Nasuruddin, 1992. The Malay Traditional Music. Dewan Bahasa Dan Pustaka, Kuala Lumpur.

3. Widjaja, A. Elizabeth, 1980. The angklung and other West Javanese Bamboo musical instruments.In Bamboo Research in Asia: Proceedings of a Workshop Held in Singapore, 2830 May 1980, Gilles Lessard and Amy Chouinard (Eds.). Ottawa: International Development Research Centre, pp: 201-204.

4. Mohd Zainal, M.R., S. Abd Samad and A. Hussain, 2005. Sound analysis of angklung: A traditional musical instrument. Proceeding MMU International Sympousam on Information and Communications Technologies, Malaysia, 2005, TS04 pp: 9-12.

5. Roederer, J.G., 1973. Introduction to the Physics and Psychophysics of Music. Springer Verlag, New York.

6. Rigden, J.S., 1985. Physics and the Sound of Music. 2nd Edn. John Wiley and Sons.

7. Berg, R.E. and D.G. Stork, 1995. The Physics of Sound. 2nd Edn. Prentice Hall, New Jersey.

8. Rossing, T.D., F.R. Moore and P.A. Wheeler, 2002. The Science of Sound. 3rd Edn. Addison Wesley, San Francisco.

9. Roads, C., 2000. The Computer Music Tutorial. The MIT Press, Massachusetts.

10. Brémaud, P., 2001. Mathematical Principles of Signal Processing. Springer Verlag, New York.

11. Zölzer, U., 1997. Digital Audio Signal Processing. John Wiley and Sons, England.

12. Smith, S.W., 1999. The Scientist and Engineer's Guide to Digital Signal Processing. 2nd Edn. California Technical Publishing, California. 